\title{
Heat Treatment Inhibits Skeletal Muscle Atrophy of Glucocorticoid- Induced Myopathy in Rats
}

\author{
Y. MORIMOTO ${ }^{1,2}$, Y. KONDO $^{3}$, H. KATAOKA ${ }^{1,4}$, Y. HONDA $^{1,2}$, R. KOZU $^{2}$, \\ J. SAKAMOTO ${ }^{5}$, J. NAKANO ${ }^{5}$, T. ORIGUCHI ${ }^{1}$, T. YOSHIMURA ${ }^{1}$, M. OKITA ${ }^{1}$ \\ ${ }^{1}$ Department of Locomotive Rehabilitation Science, Unit of Rehabilitation Sciences, Nagasaki \\ University Graduate School of Biomedical Sciences, Nagasaki, Japan, ${ }^{2}$ Department of \\ Rehabilitation, Nagasaki University Hospital, Nagasaki, Japan, ${ }^{3}$ Department of Rehabilitation, \\ Japanese Red Cross, Nagasaki Genbaku Isahaya Hospital, Isahaya-shi, Nagasaki, Japan, \\ ${ }^{4}$ Department of Rehabilitation, Nagasaki Memorial Hospital, Nagasak-shi, Nagasaki, Japan, \\ ${ }^{5}$ Department of Physical Therapy Science, Unit of Physical and Occupational Therapy Sciences, \\ Nagasaki University Graduate School of Biomedical Sciences, Nagasaki, Japan
}

Received October 3, 2014

Accepted February 20, 2015

On-line June 5, 2015

\begin{abstract}
Summary
The purpose of this study was to investigate the influence of heat treatment on glucocorticoid (GC)-induced myopathy. Eight-weekold Wistar rats were randomly assigned to the control, Dex, and Dex + Heat groups. Dexamethasone $(2 \mathrm{mg} / \mathrm{kg})$ was injected subcutaneously 6 days per week for 2 weeks in the Dex and Dex + Heat group. In the Dex + Heat group, heat treatment was performed by immersing hindlimbs in water at $42^{\circ} \mathrm{C}$ for $60 \mathrm{~min}$, once every 3 days for 2 weeks. The extensor digitorum longus muscle was extracted following 2 weeks of experimentation. In the Dex + Heat group, muscle fiber diameter, capillary/muscle fiber ratio, and level of heat shock protein 72 were significantly higher and atrogene expression levels were significantly lower than in the Dex group. Our results suggest that heat treatment inhibits the development of GC-induced myopathy by decreasing atrogene expression and increasing angiogenesis.
\end{abstract}

\section{Key words}

GC-induced myopathy • Heat treatment • Muscle fiber • Hsp72 • Capillary

\section{Corresponding author}

M. Okita, Department of Locomotive Rehabilitation Science, Unit of Rehabilitation Sciences, Nagasaki University Graduate School of Biomedical Sciences, 1-7-1 Sakamoto, Nagasaki-shi, Nagasaki
852-8520, Japan. Telephone and Fax: +81-95-819-7919. E-mail: mokita@nagasaki-u.ac.jp

\section{Introduction}

Many patients with various diseases (e.g. rheumatoid arthritis, bronchial asthma, and myasthenia gravis) are administered glucocorticoids (GCs). GCs effectively inhibit inflammation in several medical conditions. However, it is also well known that high doses and sustained administration of GCs results in various progressive side effects. Among these side effects, GC-induced myopathy is a serious complication for patients, and $60 \%$ of patients with GC-induced myopathy develop muscle weakness of proximal skeletal muscles that are severe enough to interfere with the activities of daily living (Batchelor et al. 1997). In addition, fast-twitch skeletal muscle fiber atrophy (Schakman et al. 2008, 2013), which is a characteristic of GC-induced myopathy, induces easy fatigability during exercise tasks, such as stair climbing, bicycling, and walking at a brisk pace (Lucia et al. 2008, Nogales-Gadea et al. 2012). This phenomenon disturbs the progress of rehabilitation in these patients. Although a previous study using an animal model reported that fast-twitch skeletal muscle fiber atrophy caused by GC could be improved by 
exercise (Okita et al. 2001), many patients with the severe disorder cannot exercise as expected due to aggravation of their overall disease status. Thus, it is important to develop therapies for GC-induced myopathy that do not involve exercise.

The mechanism of induction of GC-induced myopathy has been identified to some extent in recent studies (Castillero et al. 2013, Gwag et al. 2013, Rauch and Gestwicki 2014, Senf et al. 2010). Administration of GC mainly activated the major cellular proteolytic systems, particularly the ubiquitin proteasome system (UPS), through increases in MuRF1 and atrogin-1 in muscle proteolysis (Hasselgren 1999). In addition, it is possible that GC-induced myopathy is related not only to muscle protein breakdown but also to angiogenesis. Endothelial cell proliferation has been shown to be reduced by $\mathrm{GC}$, coinciding with reduced vascular endothelial growth factor (VEGF) production (Shikatani et al. 2012). These alterations resulted in a decrease in capillary number and may be related to skeletal muscle atrophy (Shikatani et al. 2012, Wagatsuma 2008).

We have previously investigated heat treatment of skeletal muscle; warming skeletal muscle to approximately $42{ }^{\circ} \mathrm{C}$ can prevent disuse muscle atrophy by increasing the expression of heat shock protein (Hsp)72, which increases more in fast-twitch muscle than in slow-switch muscle (Yoshida et al. 2013). Hsp72 overexpression prevents protein breakdown and skeletal muscle disuse atrophy through inhibition of MuRF1 and atrogin-1 (Senf et al. 2008). Heat treatment also improves vascular flow, and endothelial function involves increased expression of endothelial nitric oxide synthase (eNOS), increasing capillary number (Miyata and Tei 2010). The effect of heat treatment of skeletal muscle on Hsp72 overexpression and angiogenesis led us to hypothesize that heat treatment could prevent GC-induced myopathy by down-regulating UPS or by increasing capillary number. However, it remains unclear whether heat treatment can prevent GC-induced myopathy. Therefore, we investigated the effect of heat treatment on GC-induced muscle atrophy using a rat model.

\section{Methods}

Animals

Eight-week-old male Wistar rats (Kudo Laboratories, Saga, Japan) were used in this study. All rats were housed 2 or 3 per cage at $22-24{ }^{\circ} \mathrm{C}$ under a 12 -h light/dark cycle and allowed access to food and water $a d$ libitum. Animal care and experimental procedures were performed in accordance with the Guidelines for Animal Experimentation of Nagasaki University and with approval from the Institutional Animal Care and Use Committee (approval number: 1109050949).

\section{Experimental design}

The 32 rats used in the experiments were randomly divided into 3 groups: 1) control, 2) Dex, and 3) Dex + Heat. Rats in the Dex and Dex + Heat group $(\mathrm{n}=10 ; \mathrm{n}=12)$ were subcutaneously injected with $2 \mathrm{mg} / \mathrm{kg}$ dexamethasone (dex) (MSD, Tokyo, Japan) in the lower back 6 days per week for 2 weeks. The dose and period of injection of the dex was decided with reference to a previous study, which showed that administration of dex strongly induced muscle fiber atrophy in rat gastrocnemius muscle (Konno 2005). In addition to the dex injection, rats in the Dex + Heat group were immersed in water at $42{ }^{\circ} \mathrm{C}$ for $60 \mathrm{~min}$ as a heat treatment, once every 3 days for 2 weeks. Prior to heat treatment, rats were anesthetized with pentobarbital sodium (40 mg/kg). We previously established that this method of heat treatment significantly increased Hsp72 in the gastrocnemius muscle (Yoshida et al. 2013), and confirmed the same result in the EDL muscle. In addition, increased eNOS and capillary numbers were expected to be induced by heat treatment, because a previous study reported that they were induced by heat treatment at $41^{\circ} \mathrm{C}$ for $15 \mathrm{~min}$ in skeletal muscle (Akasaki et al. 2006). Rats in the control group $(n=10)$ were injected with saline instead of dex for the same time period as the Dex group. When rats in the Dex + Heat group were anesthetized, the same anesthetization was also provided to rats in the control and Dex groups. The experimental period had a duration of 2 weeks, and body weight was measured during this period every day.

\section{Sample preparation}

The bilateral extensor digitorum longus (EDL) muscle, which is a typical fast-twitch muscle, was extracted at the end of the experimental period. Left EDL muscles were frozen in isopentane that had been cooled to the freezing point with liquid nitrogen. Serial crosssections $(7 \mu \mathrm{m})$ were collected from each frozen muscle for histological analysis using a cryostat (CM1950; Leica, Wetzlar, Germany). Half of the right EDL muscles were homogenized in $0.01 \mathrm{M}$ phosphate buffered saline (PBS; $\mathrm{pH}$ 7.4) using a glass homogenizer. The supernatants 
were collected after centrifugal separation at $4{ }^{\circ} \mathrm{C}$ at $12,000 \times g$ for $15 \mathrm{~min}$, and the protein concentration was measured using a BCA protein Assay Kit (Pierce Biotechnology Inc., Rockford, Illinois). The final protein concentration was adjusted to $1.5 \mu \mathrm{g} / \mu \mathrm{l}$ for western blotting. The remaining halves of the right EDL muscles were immediately processed with RNA Later ${ }^{\circledR}$ (Ambion, Carlsbad, CA) for real-time reverse transcription polymerase chain reaction (rRT-PCR). All samples were stored in a deep freezer $\left(-80^{\circ} \mathrm{C}\right)$ until further analysis.

\section{Histochemical analysis}

The pathological characteristics of the muscle tissue were identified using sections stained with hematoxylin and eosin.

\section{Size of muscle fibers}

To determine the muscle fiber diameter for each fiber type, myosin ATPase staining was performed; the acid pre-incubation solution was adjusted to $\mathrm{pH} 4.5$ to classify muscle fibers into types I, IIa, and IIb (Zacharova et al. 2005, Soukup et al. 2009). The muscle fiber diameters of each fiber type were measured using Image $\mathbf{J}$ software (NIH, Frederick, MD). The diameter was defined as the maximum diameter across the lesser aspect of the muscle fiber (lesser diameter). Measurements were taken for more than 200 fibers of each type per muscle.

\section{Capillary}

The ALP reaction, employing an indoxyltetrazolium method, allowed visualization of the capillaries in the muscles (Ziada et al. 1984). Capillary number supply was evaluated by assessing the capillary/muscle fiber ratio. The capillaries and muscle fibers were counted in 10 unbiased photographs ( $\times 100$ magnification) covering the entire area of the deep layer of the muscle. For each photograph, the capillary/muscle fiber ratio was expressed as the number of capillaries per muscle fiber.

\section{Western blotting for Hsp 72}

The levels of Hsp72 in EDL muscle were measured by western blotting. Samples $(15 \mu \mathrm{l})$ from each muscle were loaded onto $12.5 \%$ sodium dodecyl sulfatepolyaclylamidegel electrophoresis (SDS-PAGE) gels, and electrophoresis was performed at $20 \mathrm{~mA}$ (constant current/gel) for $90 \mathrm{~min}$. The gel was transferred to a polyvinylidene difluoride (PVDF) membrane at a constant voltage of $40 \mathrm{~V}$ for $70 \mathrm{~min}$. Blots were blocked with $5 \%$ skim milk in $0.15 \mathrm{M}$ Tris- $\mathrm{HCl}$ buffer $(1.5 \mathrm{M}$ $\mathrm{NaCl}, 0.05 \%$ Tween-20, $\mathrm{pH} \mathrm{8.8)} \mathrm{for} 1 \mathrm{~h}$ at room temperature. After washing 5 times in buffer, the membranes were incubated overnight with primary antiHsp72 antibody (Stressgen Bioreagents Corp., Victoria, BC) diluted 1:1000 in buffer at $4{ }^{\circ} \mathrm{C}$, and then washed and incubated with horseradish peroxidase-conjugated mouse anti-rat IgG (Medical and Biological Laboratories Corp Ltd., Nagoya, JAPAN). After further washing, the reaction was made visible using a Metal Enhanced DAB Substrate Kit (Pierce Biotechnology Inc., Rockford, IL). Quantification of the bands from each immunoblot was performed using Image $\mathrm{J}$ software, and the data were expressed as a percentage of the mean of the control level.

Real-time reverse transcription polymerase chain reaction ( $R T$ - $P C R$ )

rRT-PCR analysis was performed for detection of MuRF1, Atrogin-1, VEGF, and eNOS mRNA in EDL muscle. The primers sequences used for amplification are listed in Table 1. RNA was extracted from muscle samples using a RNeasy Fibrous Tissue Mini Kit (Qiagen, Hilden, Germany) according to the manufacturer's protocol. Total RNA template was used to make cDNA using a QuantiTect ${ }^{\circledR}$ Reverse Transcription Kit (Qiagen, Hilden, Germany). Thereafter, $0.2 \mu \mathrm{l}$ of each diluted cDNA sample was used as a template for PCR amplification, using Brilliant III Ultra-fast SYBR ${ }^{\circledR}$ Green QPCR Master Mix (Agilent, Foster, CA) as a fluorogenic intercalating dye and a Mx3005P Real-Time QPCR system (Agilent, Foster, CA). PCR parameters were as follows: an initial denaturation step of $10 \mathrm{~min}$ at $95^{\circ} \mathrm{C}$ followed by 40 cycles of $15 \mathrm{~s}$ at $95^{\circ} \mathrm{C}$ and $60 \mathrm{~s}$ at $60^{\circ} \mathrm{C}$. The relative expression levels were calculated using the comparative $2^{-\Delta \Delta \mathrm{Ct}}$ method and the RNA of the housekeeping gene $\beta$-actin as a control. The control levels were arbitrarily set to 1 .

\section{Statistical analysis}

All data are presented as the mean \pm standard deviation (SD). One-way analysis of variance followed by a Bonferroni/Dunn post-hoc test was used to compare all variables among the 3 groups. Differences were considered significant at $\mathrm{p}<0.05$. 
Table 1. Oligonucleotides of primers for real-time reverse transcription PCR.

\begin{tabular}{|c|c|c|c|c|}
\hline $\begin{array}{l}\text { Gene } \\
\text { product }\end{array}$ & Forward & Reverse & $\begin{array}{l}\text { Product } \\
\text { length }\end{array}$ & $\begin{array}{c}\text { GenBank } \\
\text { No }\end{array}$ \\
\hline MuRF1 & 5'-GGAGAAGCTGGACTTCATCG-3' & 5'-CTTGGCACTCAAGAGGAAGG-3' & $133 \mathrm{bp}$ & AY059627.1 \\
\hline Atrogin-1 & 5'-CTACGATGTTGCAGCCAAGA-3' & 5'-TTCCCCCAAAGTGCAGTATC-3' & $139 \mathrm{bp}$ & AY059628.1 \\
\hline$V E G F$ & 5'-ATGCCAAGTGGTCCCAG-3' & 5'-CAATAGCTGCGCTGGTAG-3' & $94 \mathrm{bp}$ & AY702972.1 \\
\hline eNOS & 5'-TGACCCTCACCGATACAACA-3' & 5'-CTGTACAGCACAGCCACGTT-3' & $123 \mathrm{bp}$ & AB176831.1 \\
\hline$\beta$-actin & 5'-CTAAGGCCAACCGTGAAAAG-3' & 5-TCTCCGGAGTCCATCACAAT-3' & $136 \mathrm{bp}$ & AF122902.1 \\
\hline
\end{tabular}

\section{Results}

The body weights of the rats are presented in Figure 1. The administration of dex gradually decreased the body weight of rats in the Dex and Dex + Heat groups. General histological observation of the EDL muscle confirmed muscle fiber atrophy in the Dex and Dex + Heat groups. Except for muscle fiber atrophy, no pathological features were observed in the muscles of any of the rats (data not shown).

\section{Muscle fiber diameter}

Representative images of cross-sections of samples with myosin-ATPase staining are shown in Figure 2A-C. Quantitative analysis showed that the diameter of all muscle fiber types was significantly lower in the Dex group (type I, $21.6 \pm 4.0 \mu \mathrm{m}$; type IIa, $22.4 \pm$ $3.8 \mu \mathrm{m}$; type IIb, $28.5 \pm 6.5 \mu \mathrm{m}$ ) than in the control group (type I, 23.2 $\pm 4.3 \mu \mathrm{m}$; type IIa, $25.0 \pm 4.7 \mu \mathrm{m}$; type IIb, $38.8 \pm 9.3 \mu \mathrm{m})$ (Fig. 2D). In particular, the type IIb fibers showed the greatest atrophic alteration. In the Dex + Heat group, the diameters of type I and IIa fibers were significantly higher than in the Dex group, and were preserved at the same level as the controls. Only the diameter of type IIb fibers was significantly lower in the Dex + Heat group than in the control group; however, it was still higher than in the Dex group (Dex; 28.5 $\pm 6.5 \mu \mathrm{m}$ vs. Dex + Heat; $33.2 \pm 6.8 \mu \mathrm{m}$ ). Type IIb fibers showed the greatest difference between the Dex and Dex + Heat groups.

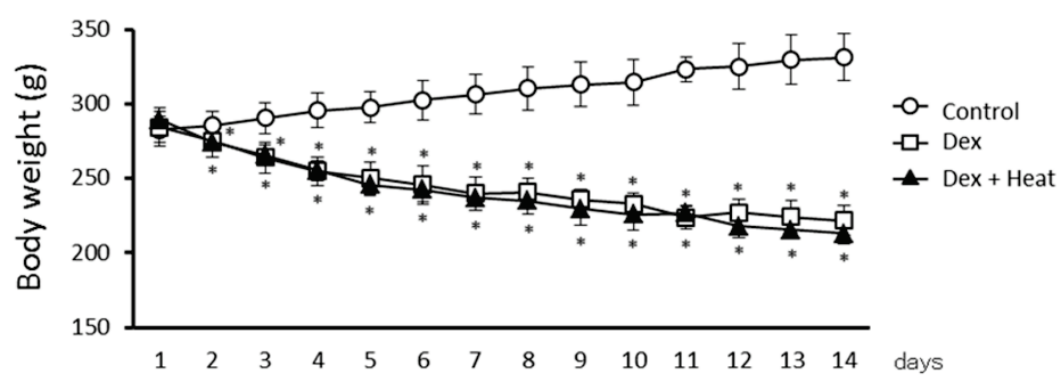

\section{Atrogene mRNA levels}

The level of MuRF1 mRNA was significantly higher in the Dex group than in the control group (Dex: $1.43 \pm 0.49$ vs. control: $1.00 \pm 0.16)$. However, the level of MuRF1 mRNA did not differ between the Dex + Heat $(0.97 \pm 0.23)$ and control groups, and was significantly lower in the Dex + Heat group than in the Dex group (Fig. 3A). The level of atrogin-1 mRNA showed the same pattern as MuRF1 mRNA (Dex, 1.61 \pm 0.48 ; Dex + Heat, $0.75 \pm 0.21$; control, $1.00 \pm 0.30$ ) (Fig. 3B).

\section{Expression of Hsp 72}

No significant difference in the concentration of Hsp72 was observed between the Dex and control groups (Dex: $91.7 \pm 61.7 \%$ vs. control: $100 \pm 60.0 \%$ ). The concentration of $\mathrm{Hsp} 72$ in the Dex + Heat group $(673.9 \pm 79.3 \%)$ was significantly higher than in the other 2 groups (Fig. 3C). Hsp72 levels were 6-fold higher in the Dex + Heat group than in the control group.

\section{Capillary}

Representative images from cross-sections with ALP staining for visualizing capillaries are presented in Figure 4A-C. The number of capillaries increased in the following order: control (108.3 \pm 26.1$)$, Dex (123.1 \pm 29.7$)$, and Dex + Heat groups (142.3 \pm 28.7$)$. Thus, the capillary/ muscle fiber ratios were significantly lower in the Dex and Dex + Heat groups than in the control group, and that in the Dex + Heat group was significantly higher than that in the Dex group.

Fig. 1. Changes in body weight during administration of dex and heat treatment for 14 days. * significantly different from controls $(p<0.05)$. Data are expressed as mean \pm SD. 

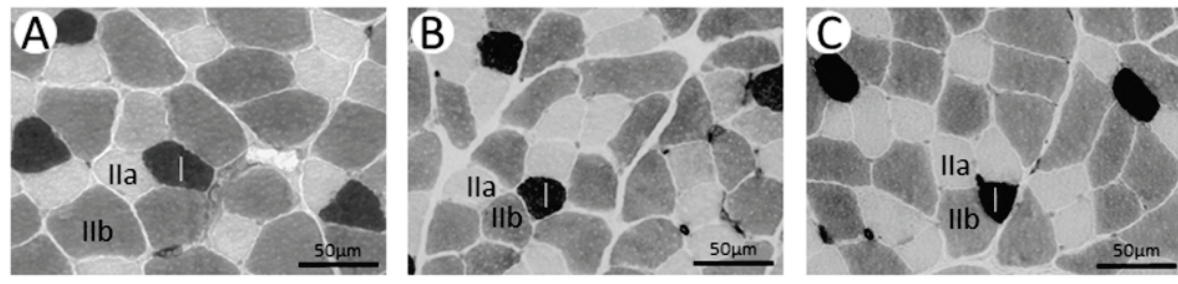

D

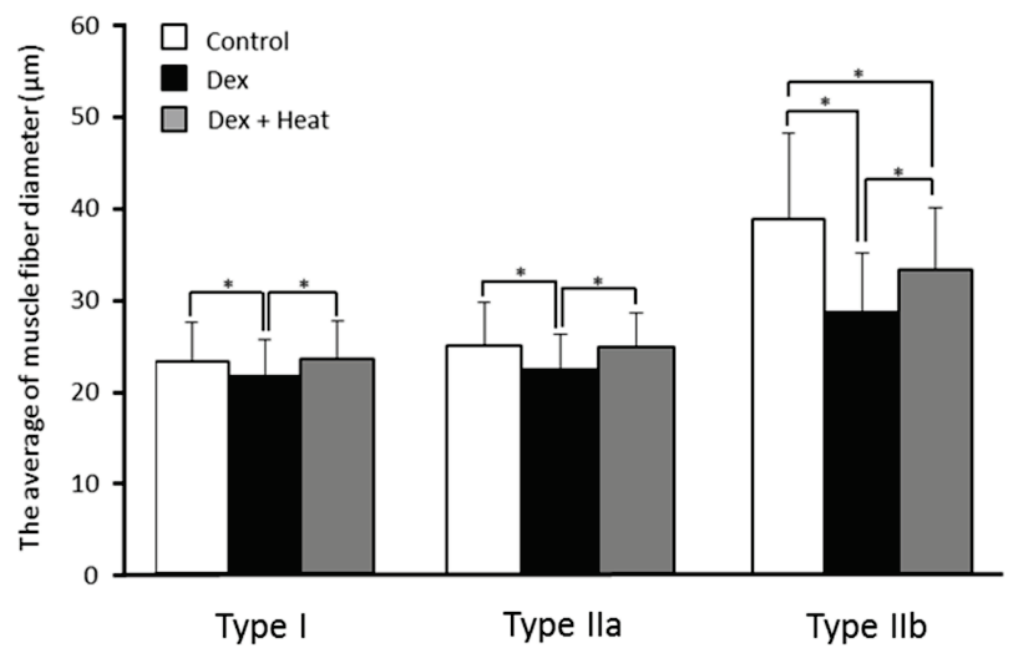

Fig. 2. Histological changes in the muscle fibers of the extensor digitorum longus muscle. Crosssections of muscle stained with myosin ATPase (pH 4.5) in the control (A), Dex (B), and Dex + Heat (C) groups. White, type I fibers; Black, type IIa fibers; Gray, type IIb fibers. (D) Changes in muscle fiber diameter following administration of dex and heat treatment. Data are expressed as mean \pm SD. $*$ significantly different $(p<0.05)$.

\section{VEGF and eNOS $m R N A$ levels}

Levels of VEGF mRNA in the Dex group were significantly lower than in the control group (Dex: $0.57 \pm 0.24$ vs. Control: $1.00 \pm 0.34)$. Levels of VEGF mRNA were also significantly lower in the Dex + Heat group $(0.49 \pm 0.16)$ than in the control group, and no significant difference was observed between the Dex and the Dex + Heat groups (Fig. 4E). In contrast, the level of eNOS mRNA was significantly higher in the Dex + Heat group than in the control or Dex groups (Dex + Heat: $1.63 \pm 0.57$ vs. control: $1.00 \pm 0.27$, Dex: $1.09 \pm 0.13$ ). No significant differences in the levels of eNOS mRNA were observed between the Dex and control groups (Fig. 4F).

\section{Discussion}

The main finding of this study is that heat treatment at $42{ }^{\circ} \mathrm{C}$ for $60 \mathrm{~min}$ inhibited the development of muscle fiber atrophy in GC-induced myopathy. The effects of heat treatment on muscle fiber atrophy in GC-induced myopathy may be associated with changes in atrogene expression, Hsp72 levels, and angiogenesis.
A

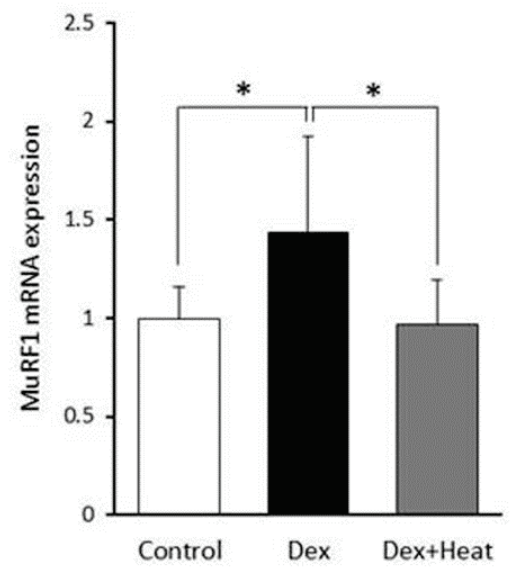

B

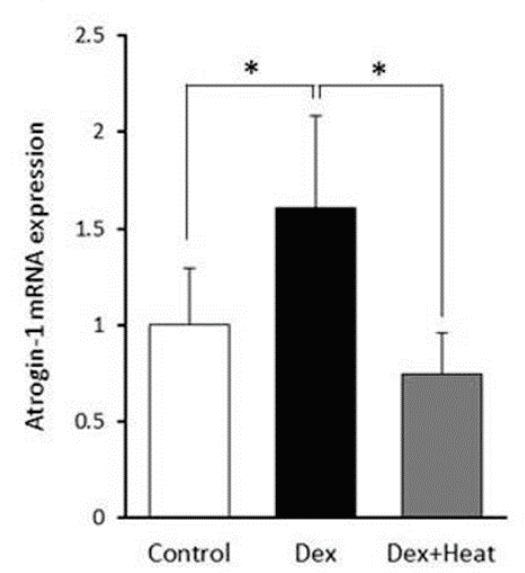

C

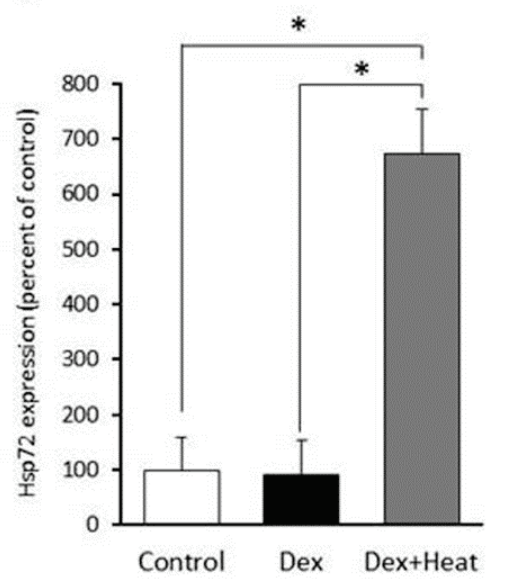

Fig. 3. Gene expression of MuRF1 (A) and atrogin-1 (B) in the extensor digitorum longus muscle. (C) Protein level of heat shock protein 72 in the extensor digitorum longus muscle. Data are expressed as mean \pm SD. * significantly different $(p<0.05)$. 

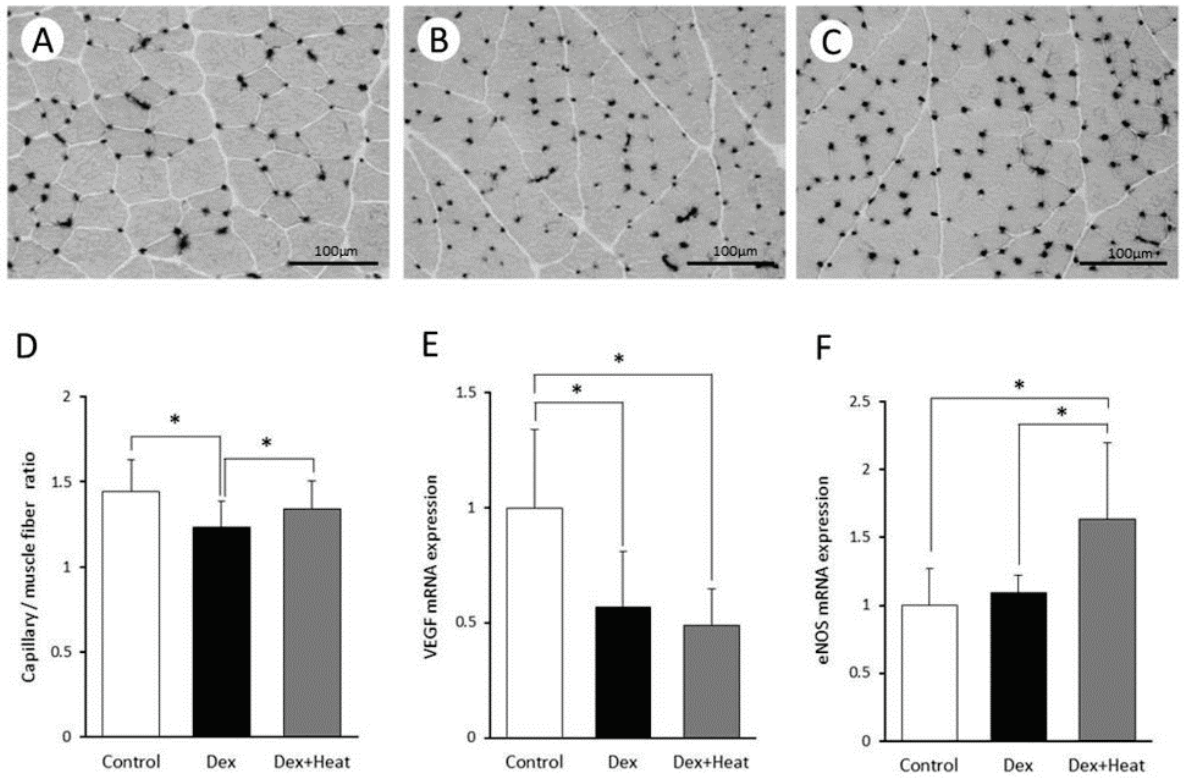

Administration of dex for 2 weeks has been reported to induce skeletal muscle fiber atrophy in rats (Konno 2005). In this study, decreases in the diameters of all muscle fiber types were confirmed in EDL muscle using the dexamethasone method described in the previous study. Of the 3 types of muscle fibers, type IIb fibers showed the most severe atrophy. Many reports have shown that fast-twitch muscle fibers, type II fibers, are more strongly affected than slow-twitch muscle fibers, type I fibers, in myopathy (Bentzinger et al. 2008, Konno 2005, Menezes et al. 2007, Risson et al. 2009, Schakman et al. 2013). Thus, rats injected with dex are considered to be a suitable model for GC-induced myopathy. The reason for the observed differences in the degree of atrophy between muscle fiber types is associated with distribution of the GC receptor; GC receptor expression is greater in fast-twitch muscle fibers than in slow-twitch muscle fibers (Shimizu et al. 2011). Therefore, we determined that EDL muscle, which mainly consists of type IIb fibers, was suitable for investigation of GC-induced myopathy. However, one limitation of this study was its classification of muscle fiber types, because myosin ATPase staining was used. Although in this study muscle fibers were classified into three types, it is well known that muscle fibers can be divided into four types: type I, IIa, IIx, and IIb. Type IIx fiber is a fast-twitch muscle fiber, and in myosin ATPase staining with acid pre-incubation $(\mathrm{pH} 4.5)$ it is stained gray, as is type IIb fiber (Soukup et al. 2009). Thus, the type IIb fiber identified in our histochemical analysis also included type IIx fibers. In recent reports, it has been suggested that type IIx fibers might be most sensitive to

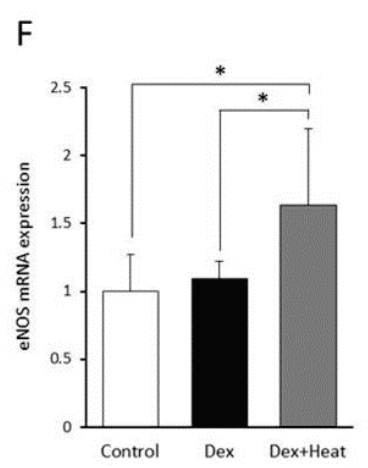

Fig. 4. Histological changes in the capillaries of the extensor digitorum longus muscle. Cross-sections of muscles stained with alkaline phosphatase reaction in the control (A), Dex (B), and Dex + Heat (C) groups. Deep dyeing indicates a capillary. (D) Changes in the capillary/muscle fiber ratios in the extensor digitorum longus muscle. Gene expression of vascular endothelial growth factor (E) and endothelial nitric oxide synthase (F) in the extensor digitorum longus muscle. Data are expressed as mean $\pm \mathrm{SD}$. * significantly different $(p<0.05)$. external effects, such as thyroid hormone status (Kopecka et al. 2014, Soukup and Smerdu 2015). Thus, glucocorticoids may have different effects on type IIx and IIb muscle fibers. In regard to this point, further study using immunohistochemical analysis with antibodies to myosin isoforms is required. On the other hand, the mechanisms underlying the development of GC-induced myopathy are not entirely clear, but the development of muscle atrophy is thought to be induced by UPS upregulation in GC-induced myopathy (Florini et al. 1996, Li et al. 2005). Recent reports have suggested that GC induces up-regulation of UPS via changes in MuRF1, atrogin-1, and muscle-specific (E3) ubiquitin ligases (Gwag et al. 2013, Schakman et al. 2008). In this study, levels of both MuRF1 and atrogin-1 mRNA were increased by administration of GC for 2 weeks in the Dex group, indicating that UPS was up-regulated in EDL muscles. The up-regulation of UPS would accelerate protein breakdown and induce muscle fiber atrophy. Interestingly, the increases in the levels of atrogin-1 and MuRF1 mRNA caused by administration of dex were inhibited by heat treatment in the Dex + Heat group. Inhibition of atrogin-1 and MuRF1 by heat treatment might reduce protein breakdown in up-regulation of UPS; atrophy of all muscle fiber types was prevented in the Dex + Heat group.

Many members of the Hsp family are known to function as molecular chaperones, meaning that they stabilize and assist in the correct folding of nascent polypeptides. In addition to their role in de novo protein folding, Hsps are involved in various aspects of proteome maintenance, including macromolecular complex 
assembly, protein transport and degradation, as well as aggregate dissociation and refolding of stress-denatured proteins. Under normal cellular conditions, Hsp levels match the overall level of protein synthesis (Kakkar et al. 2014). Hsps have received much attention for their roles as molecular chaperones for protein quality control and anti-atrophic functions (Whitham and Fortes 2008). Among the Hsps, the Hsp70 family has been extensively studied in skeletal muscle, and various roles and functions have been reported. Heat stress before hindlimb unweighting can reduce the rate of disuse muscle atrophy because Hsp72 plays a role in the control of muscle atrophy induced by reduced contractile activity (Naito et al. 2000). In this study, the expression of Hsp72 was significantly increased by heat treatment in the Dex + Heat group, as expected. It is possible that the increase in expression of Hsp72 accelerated protein synthesis, which led to the inhibition of muscle fiber atrophy in GC-induced myopathy. In addition, it has been reported that $\mathrm{Hsp} 72$ overexpression in $\mathrm{C} 2 \mathrm{C} 12$ myotubes caused an anti-atrophic effect via augmentation of p-FoxO3a and inhibition of dephosphorylation of FoxO proteins, resulting in the previously described reduction in atrogin-1 and MuRF1 (Gwag et al. 2013). As stated above, the increases in MuRF1 and atrogin-1 related to the administration of dex were inhibited by heat treatment in this study. Thus, inhibition of atrogene expression by increased expression of Hsp72 may be one of the reasons that EDL muscle fiber atrophy was prevented by heat treatment.

Administration of dex decreased the capillary/ muscle fiber ratio and VEGF levels in the Dex group. Although the details of how changes in capillary number influence skeletal muscle atrophy are not clear, it is believed that capillary number and supply of blood flow are related to regulation of muscle fiber size. For example, it has been reported that angiogenesis induced by chronic hypoxia results in muscle hypertrophy (Deveci et al. 2002). Conversely, we assumed that a reduction in capillary number induces muscle atrophy in GC-induced myopathy. A previous study has shown that GC inhibits angiogenesis and destabilizes nascent capillaries (Shikatani et al. 2012). The results of this study indicate the possibility that GC induces a decrease in capillary number via reduction in VEGF. eNOS is also an important factor in circulation, with a role in vasodilation and vascularization. Although the administration of dex for 2 weeks did not clearly decrease levels of eNOS mRNA in this study, it is possible that GC restricts vascular NO production in the heart and down-regulates the expression and/or activity of eNOS (Wallerath et al. 2004). Regarding the effect of heat treatment in the Dex + Heat group, capillary/muscle fiber ratio and levels of eNOS mRNA were increased, but VEGF was not. In a previous study, thermal therapy activated the Akt/eNOS/NO pathway and increased the capillary/muscle fiber ratio in mice with hindlimb ischemia (Miyauchi et al. 2012). VEGF protein expression decreased in the skeletal muscles of rats with GC-induced myopathy, but was unaltered by heat stress exposure (Akasaki et al. 2006, Barel et al. 2010). VEGF is one of the factors that regulates expression and activity of eNOS, but eNOS can also be up-regulated without changes in VEGF (Akasaki et al. 2006). These reports are concordant with our data, and it appears that heat treatment may have increased the capillary/muscle fiber ratio via the increase in eNOS, but not via VEGF. Further studies are required to clarify the relationship between capillary number and the inhibition of muscle fiber atrophy in GC-induced myopathy.

In conclusion, our findings showed that heat treatment maintained the levels of atrogene expression, increased Hsp72 and eNOS, and inhibited reduction in the number of capillaries, and these alterations prevented muscle fiber atrophy in GC-induced myopathy. Based on the results described above, we suggest that heat treatment is useful for patients with GC-induced myopathy. However, atrophy of type IIb muscle fibers in GC-induced myopathy, which showed the most severe atrophy, could not be prevented completely, although the levels of atrogin-1 and MuRF1 mRNA were maintained at the same levels as in the control group, and although Hsp72 was increased by more than 6-fold over the control level. Future studies will be required to clarify the mechanism underlying the inhibitive effect of heat treatment on GC-induced myopathy.

\section{Conflict of Interest}

There is no conflict of interest.

\section{Acknowledgements}

We would like to thank Shogo Nishikawa (Nanbu Hospital) and Nao Yoshida for their contributions to the data acquisition and data analysis. This study was supported by a Grant-in-Aid for Young Scientists (Startup) (No. 21800038) and a Grant-in-Aid for Young Scientists (B) (No. 40534409) from the Japan Society for the Promotion of Science. 


\section{References}

AKASAKI Y, MIYATA M, ETO H, SHIRASAWA T, HAMADA T, IKEDA Y, BIRO S, OTSUJI Y, TEI C: Repeated thermal therapy up-regulates endothelial nitric oxide synthase and augments angiogenesis in a mouse model of hindlimb ischemia. Circ J 70: 463-470, 2006.

BAREL M, PEREZ OA, GIOZZET VA, RAFACHO A, BOSQUEIRO JR, DO AMARAL SL: Exercise training prevents hyperinsulinemia, muscular glycogen loss and muscle atrophy induced by dexamethasone treatment. Eur J Appl Physiol 108: 999-1007, 2010.

BATCHELOR TT, TAYLOR LP, THALER HT, POSNER JB, DEANGELIS LM: Steroid myopathy in cancer patients. Neurology 48: 1234-1238, 1997.

BENTZINGER CF, ROMANINO K, CLOETTA D, LIN S, MASCARENHAS JB, OLIVERI F, XIA J, CASANOVA E, COSTA CF, BRINK M, ZORZATO F, HALL MN, RUEGG MA: Skeletal muscle-specific ablation of raptor, but not of rictor, causes metabolic changes and results in muscle dystrophy. Cell Metab 8: 411-424, 2008.

CASTILLERO E, ALAMDARI N, LECKER SH, HASSELGREN PO: Suppression of atrogin-1 and MuRF1 prevents dexamethasone-induced atrophy of cultured myotubes. Metabolism 62: 1495-1502, 2013.

DEVECI D, MARSHALL JM, EGGINTON S: Chronic hypoxia induces prolonged angiogenesis in skeletal muscles of rat. Exp Physiol 87: 287-291, 2002.

FLORINI JR, EWTON DZ, COOLICAN SA: Growth hormone and the insulin-like growth factor system in myogenesis. Endocr Rev 17: 481-517, 1996.

GWAG T, PARK K, KIM E, SON C, PARK J, NIKAWA T, CHOI I: Inhibition of C2C12 myotube atrophy by a novel HSP70 inducer, celastrol, via activation of Akt1 and ERK1/2 pathways. Arch Biochem Biophys 537: 21-30, 2013.

HASSELGREN PO: Glucocorticoids and muscle catabolism. Curr Opin Clin Nutr Metab Care 2: 201-205, 1999.

KAKKAR V, MEISTER-BROEKEMA M, MINOIA M, CARRA S, KAMPINGA HH: Barcoding heat shock proteins to human diseases: looking beyond the heat shock response. Dis Model Mech 7: 421-434, 2014.

KONNO S: Hydroxyl radical formation in skeletal muscle of rats with glucocorticoid-induced myopathy. Neurochem Res 30: 669-675, 2005.

KOPECKA K, ZACHAROVA G, SMERDU V, SOUKUP T: Slow to fast muscle transformation following heterochronous isotransplantation is influenced by host thyroid hormone status. Histochem Cell Biol 142: 677-684, 2014.

LI BG, HASSELGREN PO, FANG CH: Insulin-like growth factor-I inhibits dexamethasone-induced proteolysis in cultured L6 myotubes through PI3K/Akt/GSK-3beta and PI3K/Akt/mTOR-dependent mechanisms. Int $J$ Biochem Cell Biol 37: 2207-2216, 2005.

LUCIA A, NOGALES-GADEA G, PEREZ M, MARTIN MA, ANDREU AL, ARENAS J: McArdle disease: what do neurologists need to know? Nat Clin Pract Neurol 4: 568-577, 2008.

MENEZES LG, SOBREIRA C, NEDER L, RODRIGUES-JUNIOR AL, MARTINEZ JA: Creatine supplementation attenuates corticosteroid-induced muscle wasting and impairment of exercise performance in rats. $J \mathrm{Appl}$ Physiol (1985) 102: 698-703, 2007.

MIYATA M, TEI C: Waon therapy for cardiovascular disease: innovative therapy for the 21 st century. Circ $J$ 74: 617-621, 2010.

MIYAUCHI T, MIYATA M, IKEDA Y, AKASAKI Y, HAMADA N, SHIRASAWA T, FURUSHO Y, TEI C: Waon therapy upregulates Hsp90 and leads to angiogenesis through the Akt-endothelial nitric oxide synthase pathway in mouse hindlimb ischemia. Circ J 76: 1712-1721, 2012.

NAITO H, POWERS SK, DEMIREL HA, SUGIURA T, DODD SL, AOKI J: Heat stress attenuates skeletal muscle atrophy in hindlimb-unweighted rats. J Appl Physiol (1985) 88: 359-363, 2000.

NOGALES-GADEA G, CONSUEGRA-GARCIA I, RUBIO JC, ARENAS J, CUADROS M, CAMARA Y, TORRESTORRONTERAS J, FIUZA-LUCES C, LUCIA A, MARTIN MA, GARCIA-ARUMI E, ANDREU AL: A transcriptomic approach to search for novel phenotypic regulators in McArdle disease. PLoS One 7: e31718, 2012.

OKITA M, YOSHIMURA T, NAKANO J, WATABE M, NAGAI T, KATO K, EGUCHI K: Effect of treadmill exercise on muscle fibers in mice with steroid myopathy. J Jpn Phys Ther Assoc 4: 25-27, 2001. 
RAUCH JN, GESTWICKI JE: Binding of human nucleotide exchange factors to heat shock protein 70 (hsp70) generates functionally distinct complexes in vitro. J Biol Chem 289: 1402-1414, 2014.

RISSON V, MAZELIN L, ROCERI M, SANCHEZ H, MONCOLLIN V, CORNELOUP C, RICHARD-BULTEAU H, VIGNAUD A, BAAS D, DEFOUR A, FREYSSENET D, TANTI JF, LE-MARCHAND-BRUSTEL Y, FERRIER B, CONJARD-DUPLANY A, ROMANINO K, BAUCHE S, HANTAI D, MUELLER M, KOZMA SC, THOMAS G, RUEGG MA, FERRY A, PENDE M, BIGARD X, KOULMANN N, SCHAEFFER L, GANGLOFF YG: Muscle inactivation of mTOR causes metabolic and dystrophin defects leading to severe myopathy. J Cell Biol 187: 859-874, 2009.

SCHAKMAN O, GILSON H, THISSEN JP: Mechanisms of glucocorticoid-induced myopathy. J Endocrinol 197: 1-10, 2008.

SCHAKMAN O, KALISTA S, BARBE C, LOUMAYE A, THISSEN JP: Glucocorticoid-induced skeletal muscle atrophy. Int J Biochem Cell Biol 45: 2163-2172, 2013.

SENF SM, DODD SL, MCCLUNG JM, JUDGE AR: Hsp70 overexpression inhibits NF-kappaB and Foxo3a transcriptional activities and prevents skeletal muscle atrophy. FASEB $J$ 22: 3836-3845, 2008.

SENF SM, DODD SL, JUDGE AR: FOXO signaling is required for disuse muscle atrophy and is directly regulated by Hsp70. Am J Physiol Cell Physiol 298: C38-C45, 2010.

SHIKATANI EA, TRIFONOVA A, MANDEL ER, LIU ST, ROUDIER E, KRYLOVA A, SZIGIATO A, BEAUDRY J, RIDDELL MC, HAAS TL: Inhibition of proliferation, migration and proteolysis contribute to corticosterone-mediated inhibition of angiogenesis. PLoS One 7: e46625, 2012.

SHIMIZU N, YOSHIKAWA N, ITO N, MARUYAMA T, SUZUKI Y, TAKEDA S, NAKAE J, TAGATA Y, NISHITANI S, TAKEHANA K, SANO M, FUKUDA K, SUEMATSU M, MORIMOTO C, TANAKA H: Crosstalk between glucocorticoid receptor and nutritional sensor mTOR in skeletal muscle. Cell Metab 13: 170-182, 2011.

SOUKUP T, SMERDU V: Effect of altered innervation and thyroid hormones on myosin heavy chain expression and fiber type transitions: a mini-review. Histochem Cell Biol 143: 123-130, 2015.

SOUKUP T, SMERDU V, ZACHAROVA G: Fiber type composition of unoperated rat soleus and extensor digitorum longus muscles after unilateral isotransplantation of a foreign muscle in long-term experiments. Physiol Res 58: 253-262, 2009.

WAGATSUMA A: Effect of hindlimb unweighting on expression of hypoxia-inducible factor-1alpha vascular endothelial growth factor, angiopoietin, and their receptors in mouse skeletal muscle. Physiol Res 57: 613-620, 2008.

WALLERATH T, GODECKE A, MOLOJAVYI A, LI H, SCHRADER J, FORSTERMANN U: Dexamethasone lacks effect on blood pressure in mice with a disrupted endothelial NO synthase gene. Nitric Oxide 10: 36-41, 2004.

WHITHAM M, FORTES MB: Heat shock protein 72: release and biological significance during exercise. Front Biosci 13: 1328-1339, 2008.

YOSHIDA N, MORIMOTO Y, KATAOKA H, SAKAMOTO J, NAKANO J, OKITA M: Effects of combination therapy of heat stress and muscle contraction exercise induced by neuromuscular electrical stimulation on disuse atrophy in the rat gastrocnemius. J Phys Ther Sci 25: 201-206, 2013.

ZACHAROVA G, VADASZOVA A, SMERDU V, ASMUSSEN G, SOUKUP T: The effect of a unilateral muscle transplantation on the muscle fiber type and the MyHC isoform content in unoperated hind limb slow and fast muscles of the inbred Lewis rats. Physiol Res 54: 691-696, 2005.

ZIADA AM, HUDLICKA O, TYLER KR, WRIGHT AJ: The effect of long-term vasodilatation on capillary growth and performance in rabbit heart and skeletal muscle. Cardiovasc Res 18: 724-732, 1984. 